\title{
NavTEL: an open-source tool for ship routing and underkeel clearance management in estuarine channels.
}

\begin{abstract}
Sylvain Orseau ${ }^{1}$, Nicolas Huybrechts ${ }^{2}$, Pablo Tassi ${ }^{3}$, Sami Kaidi ${ }^{4}$, and Fabrice Klein ${ }^{5}$
${ }^{1}$ Cerema, Direction Technique Eau, Mer et Fleuves, 134 rue de Beauvais - CS 60039-60280 Margny-lès-Compiègne. Sorbonne Universités, Université de Technologie de Compiègne, CNRS, FRE 2012 Roberval, Centre de recherche Royallieu, CS 60 319, 60203 Compiègne cedex. Email: nicolas.huybrechts@cerema.fr

${ }^{2}$ Cerema, Direction Technique Eau, Mer et Fleuves, 134 rue de Beauvais - CS 60039-60280 Margny-lès-Compiègne. Sorbonne Universités, Université de Technologie de Compiègne, CNRS, FRE 2012 Roberval, Centre de recherche Royallieu, CS 60 319, 60203 Compiègne cedex.
\end{abstract}

${ }^{3}$ Electricité de France, R\&D Department, 6 quai Watier, BP 49, 78401 Chatou Cedex, France. Laboratoire d'Hydraulique Saint Venant (ENPC-EDF/R\&D-CEREMA), 6 quai Watier, BP 49, 78401 Chatou Cedex, France.

${ }^{4}$ Cerema, Direction Technique Eau, Mer et Fleuves, 134 rue de Beauvais - CS 60039-60280 Margny-lès-Compiègne. Sorbonne Universités, Université de Technologie de Compiègne, CNRS, FRE 2012 Roberval, Centre de recherche Royallieu, CS 60 319, 60203 Compiègne cedex.

${ }^{5}$ Grand Port Maritime de Bordeaux, 152 quai de Bacalan - CS 41320 - 33082 Bordeaux Cedex, France. 


\section{ABSTRACT}

NavTEL is a new decision support tool for the short-term (36 hours) planning of ship routes and the management of underkeel clearance in estuarine navigation channels. NavTEL used a deterministic method and is coupled with the TELEMAC-MASCARET system for numerical modeling of hydrodynamic and sediment transport in the estuary with a two-dimensional approach. In its present version, NavTEL allows to (i) prepare and launch daily simulations automatically, and (ii) to post-process simulation outputs to find the safest ship route and to predict underkeel clearances at specified locations. Because of the reliability of the results lies on the accuracy of water level predictions, numerical simulations were performed with measured river discharges, storm surge forecasts and time-varying friction coefficients for bed roughness. Even though NavTEL was initially developed for the Atlantic Port of Bordeaux located in the Gironde Estuary, its kernel has a modular structure allowing to adjust the tool to different port configurations and types of water bodies. Finally, examples of graphical outputs and reports generated by NavTEL are shown for an application of a container ship coming into the port of Bordeaux.

\section{KEYWORDS}

Ship route, Underkeel Clearance Management, Squat, Numerical modelling, NavTEL, TELEMAC-MASCARET modelling system, Gironde Estuary

\section{INTRODUCTION}

In the last few decades, maritime transportation has become the most important shipping method with a fourfold growth of the ship traffic over 20 years since early 1900s (Tournadre 2014). Ship sizes also present an impressive growth and very large container ships are now commonly used to carry merchandise between ports (Sys et al. 2008). In this context, a vigorous competition between ports arises to increase their productivity especially by providing an excellent maritime and hinterland access. This can result in substantial financial efforts for ports to maintain or deepen the navigation channel. However, these efforts have lagged behind the growth of ship size. 
Constraints for the entrance of very large ships in the navigation channel are multiple, particularly for ports located in estuaries where the balance between an efficient and safe navigation, and the maintenance of the navigation channel is often difficult to ensure. In these environments, the navigation of deep-drafted containers is firstly affected by irregular depth variation and sometimes the presence of shoals. Insufficient water depth could lead to potential disturbance on the traffic, with significant economic losses, or worse, a ship grounding. In addition, dynamic ship sinkage or buoyancy also needs to be predicted carefully. The vertical motions could be modified by (i) the increase of flow speed under the ship in shallow waters (Vantorre et al. 2017) and the proximity of banks inducing a drop in pressure (Lataire and Vantorre 2017; Zou and Larsson 2013), and (ii) the seasonal variation of the salt intrusion length inducing a decrease of the buoyancy during high river discharge periods (Barrass 2000). For turbid estuaries characterized by a pronounced Turbidity Maximum Zone (TMZ), fluid mud is commonly observed on the bottom of the navigation channel. Although navigation through unconsolidated mud layers are common in several navigation channels, highly concentrated suspension of fine sediments may lead to a modified ship behavior (Delefortrie et al. 2005; Delefortrie et al. 2010), as well as a ship resistance (Kaidi et al. 2020).

Among the large number of parameters that ensure a safe navigation, the UnderKeel Clearance (UKC) is one of the most important (Parker and Huff 1998). The UKC is defined as the available space between the ship's keel and the bottom and is often estimated as $10 \%$ of the static draft. However, in estuarine navigation channels, the minimal allowed UKC can be lower due to (i) the navigable depth affected by tide, storm surge and flowrate variation (ii) the dynamic ship sinkage and (iii) the tidal window referring to the period in which water levels are sufficient to ensure the safe passing of a ship. These factors can be accounted by considering, respectively, dredging operations in siltation areas, and variations of the water density with salinity and suspended particulate matter. Therefore, UKC maintenance is crucial as it could lead to serious economic consequences if its 
determination is inaccurate.

In maritime transport, decision support tool are multiple and used for various applications such as ship routing and scheduling (Kim and Lee 1997; Fagerholt and Lindstad 2007), port selection (Lam and Dai 2012) or ship collision (Lazarowska 2016). To the authors knowledge, few DST have been developed for ship routing and underkeel clearance management in estuarine channels, excepted for some proprietary software such as ProToel. Developed in 2009 by researchers from Ghent University, ProToel is able to determine tidal window and underkeel clearances based on both deterministic and probabilistic approaches (Eloot et al. 2009; Vantorre et al. 2013) for a specific ship. However, the tool does not include a kernel capable to simulate hydro-meteorological conditions, requiring users to provide data from measurements or forecasts at specified locations. The reliability of the route and the accuracy of underkeel clearances depends heavily on forecasts. Therefore, the application of a DST that relies exclusively on the forcing information provided by the user might difficult to plan ship routes, particularly if the period of interest presents missing or incomplete data sets.

Nowadays, logistics in ports and maritime industry has reached a high degree of complexity, requiring for practical reasons the application of analytical methods to objectively support decision-making processes. Ideally, these methods need to be embedded in a collaborative environment in the form of Decision Support Tool (DST), in order to facilitate the required port operations (Mar-Ortiz et al. 2018). The DST currently used by the port of Bordeaux only predicts water levels at a few locations considered most critical via a reconstruction of the tidal signal based on harmonic constituents. The passing hours at these locations were determined empirically and provided by tables depending on the tidal range (low or high), the route (seaward, flood landward or ebb landward) and ship speed. For the arrival of a ship, passing hours were given by tables, while for the departure an optimization procedure was performed to find the best route. The procedure consists to converge to the highest maximum allowable draft and to deduce corresponding passing 
times.

The purpose of this study is to develop an efficient DST combining the hydrodynamics and sediment transport modules of the open-source TELEMAC-MASCARET modelling system (www.opentelemac.org) and Python scripts, encapsulated in a framework capable to efficiently manage the UKC and to assist port authorities in the planning and the safe conduct of ship transit. Enhanced features of the DST are (i) its ability to provide depth-averaged velocity and water density in addition to the water level, and (ii) the using of measured river discharges and near-real time forecasting of storm surge at boundary conditions. The tool is available as an open-source code at https: //gitlab.com/orseausy/navtel and is presently in an evaluation phase for the Port of Bordeaux in France.

\section{THE PORT OF BORDEAUX AND THE GIRONDE ESTUARY}

The tool was developed as part of the Gironde XL 3D project which aims at increasing the actual knowledge of the sediment dynamics inside the Gironde Estuary and to develop a set of numerical tools to assist the Port Authority in a better regulation and coordination of ship transits. The Atlantic Port of Bordeaux is located in the Gironde estuary and is France's 7th largest seaport. It gathers 7 specialized terminals along the estuary with the most upstream terminal located $100 \mathrm{~km}$ inland (Fig. 1b). The foreign maritime traffic reach an annual average of $8.5 \times 10^{6}$ tons and is mainly represented by tankers with $52 \%$ of the overall traffic. A navigation channel of $130 \mathrm{~km}$ length and from $150 \mathrm{~m}$ to $300 \mathrm{~m}$ width connects each terminal and is maintained at a depth of $7 \mathrm{~m}$ mean lower low water (MLLW). For a period comprised between 2015 and 2016, the annual average of dredged volumes was approximately $9.5 \times 10^{6} \mathrm{~m}^{3}$ and was mainly realized by a trailing suction hopper dredger.

The Gironde Estuary is a macrotidal and convergent estuary, about $75 \mathrm{~km}$ long and $12 \mathrm{~km}$ wide at the estuary mouth, dominated by the tide and mainly fed by two tributaries: the Dordogne River and the Garonne River (Fig. 1b). These tributaries are characterized by a total catchment area of approximately $83000 \mathrm{~km}^{2}$. During the $2005-2014$ period, 
mean total discharges were $1100 \mathrm{~m}^{3} \mathrm{~s}^{-1}$ in winter and $295 \mathrm{~m}^{3} \mathrm{~s}^{-1}$ in summer (Jalón-Rojas et al. 2015). The tide is a semi-diurnal type and the mean neap and spring tidal ranges are of 2.5 and $5 \mathrm{~m}$, respectively (Bonneton et al. 2015). Water levels are measured at 9 tidal gauges placed along the estuary from Le Verdon to Bordeaux stations.

The hydrodynamics of the Gironde Estuary is mainly forced by tide and freshwater runoff while the influence of winds is not clearly determined. Along the estuary, tidal and subtidal water level variations depict an amplification mainly explained by tidal processes (Ross and Sottolichio 2016). The tide is also characterized by a flood-dominated asymmetry. However, the continuous decrease of the river discharge observed over the past 60 years induced strong changes in tidal range and tidal distortion (Schmidt 2016; Jalón-Rojas et al. 2018).

From the port of Bordeaux to the estuary mouth, the bed composition can be distributed over 3 areas: (i) a mixed facies dominated by mud (56\% of clays, $42 \%$ of silts and $2 \%$ of sands) between Bordeaux and the confluence of the Dordogne and the Garonne rivers, (ii) a mixed facies in the central estuary up to Richard and (iii) a sandy facies in the lower estuary and the estuary mouth. Fine suspended-sediments formed a turbidity maximum zone (TMZ) due to the combined action of the tidal asymmetry and vertical density gradients (van Maanen and Sottolichio 2018). Inside this zone, suspended-particulate matter (SPM) concentrations can vary between 1 and $10 \mathrm{~g} \mathrm{~L}^{-1}$ (Sottolichio and Castaing 1999). The TMZ location changes seasonally with hydrological conditions and is formed in the upper estuary during summer-autumn (Doxaran et al. 2009). With increasing freshwater inflows, TMZ shifts to the central estuary and a part can be exported to the ocean during peak floods. River flow discharges from the Garonne and Dordogne rivers have also a strong effect on the persistence and the concentration of the TMZ (Jalón-Rojas et al. 2015). Sottolichio and Castaing (1999) also noticed the presence of a secondary TMZ in the middle estuary (near Pauillac in the Fig. 1b) induced by strong local resuspensions. 


\section{THE NAVTEL FRAMEWORK}

The NavTEL decision support tool determines near real-time ship route and underkeel clearance by predicting water levels, current velocities and water density along an estuarine navigation channel. Because of its modular structure, the tool can be easily adjusted to a different port configuration. The kernel of NavTEL is composed by 2 modules named NAVIRE and TELBOT (Fig. 2). The TELBOT module prepares and launches simulations, while the NAVIRE module post-processes simulation results to determine the route and predict the squat. Additionally, NAVIRE incorporates time-varying friction coefficients for bed roughness. To ensure portability, NavTEL can be steered from the command line and does not include a graphical user interface. A description of each module of NavTEL is presented thereafter.

\section{TELBOT module: to predict hydrological and water-density conditions}

\section{The TELEMAC-MASCARET modelling system}

To predict the hydrodynamics and the sediment transport, the TELBOT module lies on two modules of the TELEMAC-MASCARET modeling system (TMS). TELBOT uses the hydrodynamics (TELEMAC-2D) and sediment transport (SISYPHE) modules. The former is dedicated to the simulation of free-surface flows and computes at each nodes water levels and flow velocity components. It also accounts bed friction, meteorological forcings such as atmospheric pressure and wind, and longitudinal salinity gradients. The latter is dedicated to the sediment transport (bed-load, suspended-load or total load) and bed evolution. It also accounts processes specific to cohesive sediments like the selfweight consolidation. The assessment of the TMS has been demonstrated through its application on a large number of coastal and estuarine cases (Bi and Toorman 2015; Brown and Davies 2010; Santoro et al. 2013; Van 2012). In this work, only suspended sediment transport processes are considered.

The hydrodynamics module is based on the solution of the 2D nonlinear depth-averaged shallow water equations by using the finite element or the finite volume approaches (Her- 
vouet 2007). The sediment transport module solves the depth-averaged sediment concentration equation. Due to the short time scale considered for the numerical simulations, bed evolution is not accounted in the current version of NavTEL.

The 2D hydrodynamic model was calibrated automatically by finding time-varying bed friction coefficients depending river discharges. Water levels are predicted with accuracy, particularly during low river discharge periods with a maximum Root Mean Square Error (RMSE) below $20 \mathrm{~cm}$ at Bordeaux. However, during high river discharge periods, the robustness of the model might decrease due to the influence of the TMZ on the estuarine bed structure (Jalón-Rojas et al. 2018). In order to provide accurate predictions for highly variable hydrological conditions, special attention is paid to the influence of the seasonal variation of the river discharge for determining the bed friction coefficients used in the hydrodynamics module.

\section{Numerical Model Setup}

The numerical domain extends over an area of $2200 \mathrm{~km}^{2}$ from the maritime part to the limit of the tide influence $170 \mathrm{~km}$ upstream in the Dordogne and Garonne rivers. The mesh is unstructured, composed of triangular elements and is refined at the navigation channel, fluvial areas and at the estuary mouth. Element sizes range from $300 \mathrm{~m}$ in the maritime part to $80 \mathrm{~m}$ in refined areas to better characterize the flow patterns.

Numerical simulations are performed for a period of 18 days including a spin-up period of 15 days and a forecast period of 3 days from the date of the request. The spin-up period allows to distribute salinity and suspended-sediments depending hydrological conditions to reach a state with the correct salt intrusion length and the right location of the TMZ. However, the salinity field has to be initialized at time $t=0$ depending freshwater inflow. For this, the estuary was divided into 4 zones of constant salinity. For each zone, an empirical relationship with river discharge was established and allows to automatically set salinity values. To reproduce the formation of TMZ, $2.6 \times 10^{6}$ tons of mud were placed in the central estuary (Fig.1e) as proposed by Sottolichio and Castaing (1999). 
For the maritime boundary, astronomical tides are reconstructed from tidal atlases including 46 harmonic constituents (Pairaud et al. 2008) and are coupled with a large-scale storm surges model from Météo-France combining the barotropic version of HYCOM code and the atmospheric model ARPEGE. The storm surge values are provided every hour near the Cordouan station (Lat: 45.5915, Lon: -1.4303, Fig. 1c). For fluvial boundaries, measured river discharges were imposed during the spin-up period, while the average of the last 5 days were used for the forecast period.

The bottom friction is parameterized by the Manning-Strickler formulation, distributed over 7 zones depicted in Figure 1c. During the simulation, friction coefficient values $K$ are modified automatically by empirical laws depending the variation of river discharge. Their values may also be set constant by the user.

\section{TELBOT Workflow}

The TELBOT module is composed by a set of Python subroutines and bash scripts used to prepare and launch simulations.

The first step consists in creating the TELEMAC-2D and SISYPHE steering files containing numerical and physical information such as the time-step, the friction coefficient and the eddy viscosity parameterization, as well as the input/output filenames. These filenames referred to the mesh (binary file), the boundary conditions (ASCII file), result files (binary file) and optional data files (ASCII format). The second step is to create optional data files containing river discharge and storm surge values. River discharges are downloaded on the national website https://www.vigicrues.gouv.fr/ in xml format at the Pessac and La Réole stations located at fluvial boundaries. The same procedure is applied to obtain storm surge values near the Cordouan station (Fig. 1b).

Once all required files are created, simulations are performed and numerical results are stored in a binary filename SELAFIN (slf format). Model results are kept up to 3 days before deletion and are available to be used by the NAVIRE module to determine the ship route and underkeel clearances. 


\section{NAVIRE: to plan routes and to manage underkeel clearance (UKC)}

\section{Route Planning}

Planning the traffic in the navigation channel is of major interest for port authorities to ease decision making process and therefore improve their productiveness. It might consist on providing precise information about tidal windows and delivering a panel of routes including the safest choice. Following guidance, the ship's master will be able to choose the most convenient ship's passage and anticipate the minimum UKC recommended by the port.

In NAVIRE, route planning lies on the prediction of water levels obtained from the astronomical tide and storm surge forecasts computed by the module TELBOT. This prediction allows to determine the minimal water depth requirement at selected locations (Fig. 1b) for safe passage and thus to delimit the tidal window. Depending on the longitudinal variation of the ship speed, different routes and corresponding passing hours can be provided by the port authorities. In order to find the safest route for ship coming into or leaving the port, an optimization procedure based on the convergence to the highest maximum allowable draft is then performed. For undocumented estuarine channels, the longitudinal variations of the ship speed can be established based on the Automatic Identification System (AIS) tracking system and for different hydrological conditions.

\section{Prediction of squat and management of underkeel clearance}

The specification of the maximum allowable draft and minimum UKC required by the port is a subtle balance between financial benefits by optimizing ship traffic and the insurance of a safe navigation to avoid delays or grounding. UKC varies along the ship route and is determined by the charted depth, water level and the dynamic draft considering the ship squat. The ship squat is defined as the sinkage of the ship due to pressure variations along the hull and exacerbated in shallow waters (Debaillon 2010). UKC can be formulated on either deterministic or probabilistic approaches. For a deterministic approach, the value of the water depth minus the static draft of the ship or gross UKC is determined 
by the channel dimensions and the ship speed range. For a probabilistic approach, the gross UKC is based on an acceptable probability of bottom touch. For NAVIRE, the deterministic approach was adopted.

To ensure a minimum water depth, the UKC can be estimated using only the static draft and predicted water level. However, changes in the channel configuration and the water density, particularly marked in estuarine channels, can produce upward or downward vertical forces inducing different values of squat. Provide a squat prediction even with a simple formulation seems crucial to inform the pilots on the risks. Predictions of ship squat are mainly govern by channel and ship dimensions, and the relative speed of the ship in water (Barrass and Derrett 2012). Along an estuarine channel, cross-sections are generally variable and can be characterized as (i) unrestricted channels, (ii) restricted channels or (iii) canals (Briggs et al. 2009). These channel types differ according to their proximity to the channel margins and bottom position, width, and bank slopes. In most cases, the ship squat is expected to vary as the square of the relative speed of the ship in water (Briggs et al. 2009) and becomes significant when the ratio between the water depth to the ship draft is $<1.5-2$.

In NAVIRE, the squat is determined by empirical formulas recommended by the Permanent International Association of Navigation Congresses (PIANC) during the designing of a navigation channel (Briggs et al. 2009). These formulas can be divided into two groups, according to the phases of the design process, namely the concept design phase and the detailed design phase. The first group includes simple formulations from the International Commission for the Reception of Large Ships (ICORELS), Barrass (Barrass 1979) and Yoshimura (Yoshimura 1986). The second group includes formulations to evaluate the squat and to perform a statistical analysis such as Eryuzlu (Eryuzlu et al. 1994), Huuska/Guliev (Huuska 1976) or Römisch (Römisch 1989). These formulations provide predictions of squat at the bow $S_{B}$, excepted the Römisch formulation which gives squat at the stern $S_{S}$. However, the use of these formulas are constrained by the channel type and 
dimensionless parameters describing ship dimensions relative to the channel dimensions. The user should be informed of these constraints and the relevance of their applications when predicting the squat. In some cases, these constraints can be severely restrictive.

The computed squat values can be adjusted by accounting the effect of the water density. For this, we consider that the vertical density gradient follows a profile comprised between a linear and a quadratic approximation (Ali et al. 2018; Kaidi et al. 2020). The following equations were obtained for a container ship model $(\mathrm{KCM})$ and are used by NavTEL to predict the minimum and maximum sinkage $\left(S_{1}\right.$ and $S_{2}$, respectively) with the density effect. However, in its current version, NavTEL cannot adjust the squat for other ship catgories.

$$
\begin{aligned}
& S_{1}=S_{0}+\alpha_{1} \Delta \rho \\
& S_{2}=S_{0}+\alpha_{2} \Delta \rho
\end{aligned}
$$

where $S_{0}$ is the reference sinkage computed with only the dimensions of the ship and the channel, $\Delta \rho$ is the density gradient, and $\alpha_{1}$ and $\alpha_{2}$ are coefficients depending on the ship's hull form. For the container ship model (KCM), the values of these coefficients are of $1.35 \times 10^{-3} \pm 3.8 \%$ and $9 \times 10^{-4}$, respectively.

\section{NAVIRE Workflow}

The NAVIRE module is composed of Python scripts used to post-process numerical model results, to find the optimal route and to determine the underkeel clearance with the static or the dynamic draft.

The communication between the port authority and ships is based on email exchanges (Fig. 2). The first step consists to query received emails at the address specified by the user. In this way, the user can choose different requests (emails) for the specified simulation. Emails must contain criteria for navigation (date, hour, destinations and routes) and for the ship (type, length, width, static draft and speed). Once the required specifications 
are automatically extracted from the body of the email, NavTEL postprocesses the numerical model results. The tool extracts the hydro-sedimentary variables, e.g. water depth, water surface elevation, flow velocity, salinity, and mass-concentration at a given interval (set by default equal to 5 minutes for the current version of NavTEL) of the simulation over the computational domain.

Depending on the shipping route, e.g. landward or seaward, NAVIRE will determine the passing time at each location and extract the hydro-sedimentary variables. With the chart datum and the static draft information, a first estimation of the underkeel clearance at each stations is provided. Optional variables can be used in the model to improve the determination of underkeel clearances, for example by considering the water density to predict the squat. Once the computation of the underkeel clearance is performed, NAVIRE generates a route report in pdf format including passing time, water level, water density, and underkeel clearance at selected locations.

\section{MODEL PERFORMANCE}

The ability of the numerical model at reproducing water levels is assessed based on the Mean Square Error (MSE). To this goal, the configuration considering only astronomical tides (AT) and the NavTEL configuration considering astronomical tides, predicted storm surges, measured river discharges and time-varying friction coefficients for bed roughness (NavTEL) were considered:

$$
\operatorname{MSE}(f, x)=\frac{1}{N} \sum_{n}^{N}\left(f_{n}-x_{n}\right)^{2}
$$

where $f_{n}$ is the prediction, $x_{n}$ is the measured water levels, the Root Mean Square Error (RMSE):

$$
\operatorname{RMSE}(f, x)=\sqrt{\operatorname{MSE}(f, x)}
$$

and the Skill Score (SS):

$$
\mathrm{SS}=\left(1-\frac{\operatorname{MSE}(f, x)}{\operatorname{MSE}(r, x)}\right)
$$


where $r$ is the average of measured water levels over the observation period (Murphy and Epstein, 1989).

The period used to assess the model performance was determined based on the availability of storm surges information and covered a six months period of 2015 (from 04/01 to 11/01). This period does not includes river floods usually observed between December and May, but river discharges ranged from 125 to $2860 \mathrm{~m}^{3} \mathrm{~s}^{-1}$ providing varied hydrological conditions to demonstrate the robustness of the model. For the overall period, the storm surge has averaged $-5.2 \mathrm{~cm}$ and described storm events on $05 / 05,08 / 24$ and 09/16 with values above $30 \mathrm{~cm}$.

Comparison between measured and predicted water levels were performed using tidal gauge records at 9 stations distributed along the navigation channel (Fig. 1b). For clarity, only Le Verdon, Pauillac and Bordeaux stations are showed in Figures 3 and 4. These stations were chosen for their locations covering the whole navigation channel and thus the propagation of tide up to the most upstream terminal (Bordeaux station).

At the Verdon station, near the estuary mouth, both the AT and NavTEL configurations provide accurate predictions of water level for the overall period, with RMSEs of 13 and $15 \mathrm{~cm}$ and SS values of 0.99 and 0.98 , respectively (Fig. 3a, d). For the AT configuration, the water level predictions are accurate, but tidal ranges are slightly overestimated inducing maximum errors at high and low tides. A similar observation can be made for the NavTEL configuration, particularly for high river discharges where differences with the AT configuration are highest. However, the integration of predicted storm surges in the NavTEL configuration allows to reproduce the abnormal variation of seawater. For a deepwater terminal such as the Verdon station, this improvement is not crucial, but for further downstream and depth-limited terminals like Pauillac station, surge storms can have an enormous impact on the accurate prediction of the water depth due to channel convergence and shallow-water effects.

At the Pauillac station, errors increase for both the AT and NavTEL configurations, with 
RMSE values of 19 and $20 \mathrm{~cm}$ and skill score (SS) values of 0.98 , respectively. For the AT configuration, high waters levels are better predicted than low waters levels. At Le Verdon station, the NavTEL configuration tends to overestimate high and low water levels, where maximum level differences with measurements are observed during flood periods, with values up to $87 \mathrm{~cm}$.

At the Bordeaux station, located approximately $150 \mathrm{~km}$ downstream the Cordouan station, the integration of multiple harmonic constituents in both numerical simulations allowed to accurately reproduce the tidal asymmetry. For the AT configuration, water levels are overestimated for high water levels, and underestimated for low water levels (Fig. 3c), with a RMSE a value of $31 \mathrm{~cm}$ and a SS of 0.96 . For the NavTEL configuration, the RMSE value is equal to $22 \mathrm{~cm}$, a value close to that computed for the Pauillac station (Fig. 3f), and a SS of 0.98. Possible factors that influence a better water level prediction are (i) the integration of measured values for river discharges that affect tidal damping into the model, (ii) the accounting of the storm surge information, and (iii) the time-varying friction coefficients depending on river discharges which allows a better representation of the tide propagation and therefore a more accurate estimation of the tidal range.

Computed RMSEs at selected stations are presented in Table 1. For the AT configuration, errors increase continuously, inducing a maximum RMSE of $31 \mathrm{~cm}$ and a minimum SS of 0.96 at the Bordeaux station. For all stations, more accurate predictions are obtained in the estuary mouth zone, e.g. at Le Verdon station. For the NavTEL configuration, SS values never decrease below 0.98 and RMSE values are more homogeneous along the navigation channel, with values ranging between 15 and $22 \mathrm{~cm}$. This observation suggests little variation of the accuracy of water level predictions respected to the hydrological conditions.

Predictions with the NavTEL configuration are at least as accurate as the configuration currently used by the GPMB for the lower and the intermediate estuary, but better reproduce water level variations in the upper estuary depending meteorological and hydrolog- 
ical conditions. Similar behaviour is found for the tidal phase, as shown in Fig. 4. The Verdon and Pauillac gauging stations do not show significant improvements with, respectively, $58 \%$ and $46 \%$ of high waters that are better predicted by the NavTEL configuration. However, for high waters have occurred during a period with a total river discharge superior to $900 \mathrm{~m}^{3} \mathrm{~s}^{-1}$ (averaged over the last six decades), previous rates increase to $60 \%$, $64 \%$ and $85 \%$ for Le Verdon, Pauillac and Bordeaux stations, respectively. This result highlights the influence of measured river discharges and time-varying friction coefficients in the numerical simulations, allowing a better parameterization of the flow resistance and therefore a more accurate representation of the tidal wave celerity. It also confirms that NavTEL is more suited for a large range of hydrological conditions, while the actual configuration used by the GPMB provides equivalent or slightly better predictions only for low river discharges.

\section{APPLICATION FOR A SHIP COMING INTO THE PORT OF BORDEAUX}

In coastal and river channels, ship navigation is generally allowed for a minimum UKC of $10 \%$ of the static draft. However, in estuaries the presence of soft bottom allows to reduce this value to $0.8 \mathrm{~m}$. Based on these restrictions, a tidal window is determined and stored in html format for easy and clear reading (Fig. S1). This information aims to assist pilots in their decisions for the planning of the optimal ship route. It contains passing hours of all possible routes at 5-min intervals and corresponding underkeel clearances. NavTEL also generates a report in pdf format (Fig. S2) containing the suggested passing hours at selected locations to ensure a safe transit along the channel. It also provides predictions of water level, underkeel clearance and water density considering salinity and suspended particulate matter.

As an example, NavTEL is applied for an operation requesting the arrival of a container ship at the Bassens terminal (Fig. 1b) on date 03/20/2020 at 17:30. It has a length of $134 \mathrm{~m}$, a breadth of $23 \mathrm{~m}$, a static draft of $8.3 \mathrm{~m}$, and a block coefficient of 0.6 . The variation of ship speed is included in the passing hours determined empirically by the port and is 
assumed to be $\leq 12$ knots.

The temporal mean of the salinity over the numerical domain is provided to evaluate the salt intrusion length and possible density effects on sinkage during the forecast period. From the $03 / 19$ to the $03 / 21$, the mean limit of the salt intrusion is located in the lowest estuary downstream the Richard station (Fig. 5). The proposed location seems to be consistent with hydrological conditions characterized by the averaged value of the total river discharge of the forecast period (equal to $1354 \mathrm{~m}^{3} \mathrm{~s}^{-1}$ for this example).

According to the tidal window, the earliest and the latest time to enter into the estuary are 12:37 and 15:47 respectively, for date 03/20 (Fig. S1). Based on UKCs, the optimal route started at $14: 17$ with a maximum allowable draft of $9.88 \mathrm{~m}$ at Pachan station (Fig. 1b). These observations are confirmed by the graphical output displaying the variation of the allowable draft along the navigation channel and for the predicted period (Fig. 6). Figure 6 assists pilots in their decisions by quickly visualizing the tidal windows, showing the static draft on red lines as well as the entire route and the departure time of the safest path on the black line. The location where the maximum allowable draft was found is also displayed along the line. Furthermore, it shows that Pauillac and Pachan are the selected locations which determines if a ship can safely navigate within the Gironde Estuary, as the length of tidal windows are generally short for the given navigability condition. It is therefore important to accurately predict the water levels at different stations located on the ship route, in order to optimize the length of the tidal window.

The route report (Fig. S2) provided by NavTEL indicates a transit time of 3 hours and 53 minutes and a hour of arrival 40 minutes after the high tide at the Bordeaux station. During the transit, highest water levels are observed at downstream stations e.g. from B12A to By stations, ensuring a navigation at high water and at the beginning of the ebb phase. During this navigation phase the flow velocity is decreased until the high water slack occurrence, easing the berthing operation. The lowest underkeel clerances are identified at Pachan and Pauillac stations (Fig. 1) with values of $1.6 \mathrm{~m}$ and $1.7 \mathrm{~m}$, respec- 
tively. As shown in Fig. 7d, squat values predicted with the Yoshimura formulation are approximately equal to $0.8 \mathrm{~m}$ for all stations.

\section{CONCLUSIONS AND PERSPECTIVES}

In this study, NavTEL, a new decision support tool to assist pilots and port authorities in the planning of ship route and the management of the underkeel clearance was introduced. Its originality lies in a combination of numerical tools and Python scripts dedicated to the automation of simulations and the post-processing of outputs to obtain water level, current velocity, salinity and water density for a given water body. In its current version, NavTEL is based on a deterministic approach to compute the hydrodynamics and sediment transport in an estuarine zone for short-term navigation plannings. To obtain accurate predictions of the water level, the tool retrieves measured river discharges and storm surge forecasts. Results highlight the versatility of NavTEL to predict the range and phase of a tide for various hydrological conditions along the navigation channel. An application for the port of Bordeaux shows different NavTEL's outputs, in particular the determination of the tidal window with possible navigable routes, as well as a navigation report providing passing hours at selected locations for the safest route and corresponding underkeel clearances.

Even though NavTEL was initially developed for the Atlantic Port of Bordeaux, its kernel has a modular structure allowing to adjust the tool to different port configurations and types of water bodies. Further developments include long-term planning of ship route based on a probabilistic approach, ship manoeuvrability and statistical analysis of the simulation output to estimate uncertainty predictions. 


\section{Acknowledgments}

The developement of NavTEL was enabled by funding from the Connecting Europe Facility (CEF) - Transport Sector under agreement (Innovation and Networks Executive Agency) No. INEA/CEF/TRAN/M2014/1049680 through the project Gironde XL. The authors thanks Météo-France and the Service Hydrographique et Océanographique de la Marine (SHOM) for providing storm surge and weather forecasts. 


\section{SUPPLEMENTAL DATA}

As an example, NavTEL provides following possible routes with corresponding maximum allowable draft (Fig. S1) and a route report containing relevant informations for navigation (Fig. S2). Both files are available online in the ASCE Library (ascelibrary.org). 


\section{ROUTE REPORT}

\begin{tabular}{llll}
\hline Date & 20/03/20 & Static draft: & 8.3 \\
Destination: & BASSENS AVAL & High tide at referent harbor: & $17 \mathrm{~h} 30$ \\
Route: & FLOOD LANDWARD & Maximum allowable draft: & 9.88 \\
Speed: & 12 & Tidal coefficient: & 50 \\
\hline
\end{tabular}

\begin{tabular}{|c|c|c|c|c|c|c|c|c|}
\hline $\mathrm{KP}$ & Critical Locations & Date & Hour & Z & Water Level & UKC & Density & Squat \\
\hline 92.75 & B12A & $20 / 03$ & $14 \mathrm{~h} 17$ & & & & & \\
\hline 77.8 & B20 & $20 / 03$ & $14 \mathrm{~h} 51$ & & & & & \\
\hline 75.9 & RICHARD & $20 / 03$ & $14 \mathrm{~h} 57$ & 7.4 & 4.64 & 3.0 & 998.3 & 0.8 \\
\hline 71.5 & B25 & $20 / 03$ & $15 \mathrm{~h} 09$ & & & & & \\
\hline 70.7 & GOULEE & $20 / 03$ & $15 \mathrm{~h} 12$ & 7.2 & 4.65 & 2.8 & 998.3 & 0.8 \\
\hline 70.4 & BY & $20 / 03$ & $15 \mathrm{~h} 13$ & 7.0 & 4.51 & 2.4 & 998.3 & 0.8 \\
\hline 68.5 & B29 & $20 / 03$ & $15 h 18$ & & & & & \\
\hline 64.8 & LAMENA & $20 / 03$ & $15 \mathrm{~h} 29$ & 7.1 & 4.44 & 2.5 & 998.3 & 0.8 \\
\hline 63.0 & Lamena & $20 / 03$ & $15 \mathrm{~h} 34$ & & & & & \\
\hline 59.8 & LA MARECHALE & $20 / 03$ & $15 \mathrm{~h} 43$ & 7.1 & 4.41 & 2.4 & 998.3 & 0.8 \\
\hline 56.9 & SAINT ESTEPHE & $20 / 03$ & $15 \mathrm{~h} 52$ & 7.3 & 4.36 & 2.6 & 998.3 & 0.8 \\
\hline 47.3 & PAUILLAC & $20 / 03$ & $16 \mathrm{~h} 19$ & 6.3 & 4.49 & 1.7 & 998.3 & 0.8 \\
\hline 47.0 & Port Plaisance Pauillac & $20 / 03$ & $16 h 19$ & & & & & \\
\hline 43.8 & SAINT JULIEN & $20 / 03$ & $16 \mathrm{~h} 28$ & 6.4 & 4.48 & 1.8 & 998.3 & 0.8 \\
\hline 41.5 & BEYCHEVELLE & $20 / 03$ & $16 \mathrm{~h} 35$ & 6.7 & 4.49 & 2.1 & 998.3 & 0.8 \\
\hline 38.3 & CUSSAC & $20 / 03$ & $16 \mathrm{~h} 44$ & 6.9 & 4.49 & 2.3 & 998.3 & 0.8 \\
\hline 35.8 & Ile Verte & $20 / 03$ & $16 \mathrm{~h} 50$ & & & & & \\
\hline 35.7 & ILE VERTE & $20 / 03$ & $16 \mathrm{~h} 51$ & 7.4 & 4.39 & 2.7 & 998.3 & 0.8 \\
\hline 30.9 & ROQUE DE THAU & $20 / 03$ & 17h02 & 7.8 & 4.36 & 3.1 & 998.3 & 0.7 \\
\hline 26.9 & BEC AVAL & $20 / 03$ & $17 \mathrm{~h} 13$ & 6.7 & 4.3 & 1.9 & 998.3 & 0.8 \\
\hline 25.7 & Potence Bec & $20 / 03$ & $17 \mathrm{~h} 15$ & & & & & \\
\hline 24.1 & BEC AMONT & $20 / 03$ & $17 \mathrm{~h} 19$ & 6.8 & 4.29 & 2.0 & 998.3 & 0.8 \\
\hline 20.4 & Esso & $20 / 03$ & $17 \mathrm{~h} 27$ & & & & & \\
\hline 19.4 & BELLERIVE & $20 / 03$ & 17h32 & 6.7 & 4.28 & 1.9 & 998.3 & 0.8 \\
\hline 18.8 & PACHAN & $20 / 03$ & 17h35 & 6.4 & 4.28 & 1.6 & 998.3 & 0.8 \\
\hline 17.4 & CAILLOU & $20 / 03$ & $17 \mathrm{~h} 42$ & 6.6 & 4.29 & 1.8 & 998.3 & 0.8 \\
\hline 16.8 & B66 & $20 / 03$ & $17 \mathrm{~h} 44$ & & & & & \\
\hline 12.3 & GRATTEQUINA & $20 / 03$ & $18 \mathrm{~h} 02$ & 7.4 & 4.28 & 2.6 & 998.3 & 0.8 \\
\hline 10.0 & BASSENS AVAL & $20 / 03$ & $18 \mathrm{~h} 10$ & 7.4 & 4.29 & 2.6 & 998.3 & 0.8 \\
\hline 10.0 & B67 & $20 / 03$ & $18 \mathrm{~h} 10$ & & & & & \\
\hline
\end{tabular}




\section{REFERENCES}

Ali, M., Kaidi, S., and Lefrancois, E. (2018). "Effect of the muddy area on the surface wave attenuation and the ship's squat.." Proc. 39th Ibero-Latin American Congress on Computational Methods in Engineering., Compiègne, France.

Barrass, B. (2000). Ship Stability: Notes and Examples. Elsevier Science.

Barrass, C. (1979). "The phenomenon of ship squat." International Shipbuilding Progress, 26(294), 44-47.

Barrass, C. and Derrett, D. (2012). Ship Stability for Masters and Mates. ButterworthHeinemann.

Bi, Q. and Toorman, E. (2015). "Mixed-sediment transport modelling in scheldt estuary with a physics-based bottom friction law." Ocean Dynamics, 65(4), 555-587.

Bonneton, P., Bonneton, N., Parisot, J.-P., and Castelle, B. (2015). "Tidal bore dynamics in funnel-shaped estuaries." Journal of Geophysical Research: Oceans, 120(2), 923-941.

Briggs, M., Vantorre, M., Uliczka, K., and Debaillon, P. (2009). Prediction of squat for underkeel clearance. World Scientific.

Brown, J. and Davies, A. (2010). "Flood/ebb tidal asymmetry in a shallow sandy estuary and the impact on net sand transport." Geomorphology, 114(3), 431-439.

Debaillon, P. (2010). "Numerical investigation to predict ship squat." Journal of Ship Research, 54(2), 133-140.

Delefortrie, G., Vantorre, M., and Eloot, K. (2005). "Modelling navigation in muddy areas through captive model tests." Journal of Marine Science and Technology, 10, 188-202.

Delefortrie, G., Vantorre, M., Eloot, K., Verwilligen, J., and Lataire, E. (2010). "Squat prediction in muddy navigation areas." Ocean Engineering, 37(16), 1464-1476.

Doxaran, D., Froidefond, J.-M., Castaing, P., and Babin, M. (2009). "Dynamics of the turbidity maximum zone in a macrotidal estuary (the gironde, france): Observations from field and modis satellite data." Estuarine, Coastal and Shelf Science, 81(3), 321332. 
Eloot, K., Vantorre, M., Richter, J., and Verwilligen, J. (2009). "Development of decision supporting tools for determining tidal windows for deep-drafted vessels." Marine navigation and safety of sea transportation, A. Weintrit, ed., CRC Press, 227-234.

Eryuzlu, N. E., Cao, Y. L., and D’Agnolo, F. (1994). “Underkeel requirements for large vessels in shallow waterways." Proc. 28th Int. Navi. Cong., PIANC, Sevilla, Spain, 1725.

Fagerholt, K. and Lindstad, H. (2007). "Turborouter: An interactive optimisation-based decision support system for ship routing and scheduling." Maritime Economics and Logistics, 9(3), 214-233.

Hervouet, J.-M. (2007). Hydrodynamics of Free Surface Flows: Modelling with the finite element method. John Wiley \& Sons, Ltd.

Huuska, O. (1976). "On the evaluation of underkeel clearances in finnish waterways.

Jalón-Rojas, I., Schmidt, S., and Sottolichio, A. (2015). "Turbidity in the fluvial gironde estuary (southwest france) based on 10-year continuous monitoring: Sensitivity to hydrological conditions." Hydrology and Earth System Sciences, 19(6), 2805-2819.

Jalón-Rojas, I., Sottolichio, A., Hanquiez, V., Fort, A., and Schmidt, S. (2018). "To what extent multidecadal changes in morphology and fluvial discharge impact tide in a convergent (turbid) tidal river." Journal of Geophysical Research: Oceans, 123(5), 32413258.

Kaidi, S., Lefrançois, E., and Smaoui, H. (2020). "Numerical modelling of the muddy layer effect on ship's resistance and squat." Ocean Engineering, 199.

Kim, S.-H. and Lee, K.-K. (1997). "An optimization-based decision support system for ship scheduling." Computers and Industrial Engineering, 33(3-4), 689-692.

Lam, J. S. L. and Dai, J. (2012). "A decision support system for port selection." Transportation Planning and Technology, 35(4), 509-524.

Lataire, E. and Vantorre, M. (2017). "Hydrodynamic interaction between ships and restricted waterways." Transactions of the Royal Institution of Naval Architects Part A: 
International Journal of Maritime Engineering, 159, 77-87.

Lazarowska, A. (2016). "A new deterministic approach in a decision support system for ship's trajectory planning." Expert Systems with Applications, 71.

Mar-Ortiz, J., Gracia, M., and Castillo-García, N. (2018). Challenges in the Design of Decision Support Systems for Port and Maritime Supply Chains. springer, 49-71.

Pairaud, I., Lyard, F., Auclair, F., Letellier, T., and Marsaleix, P. (2008). "Dynamics of the semi-diurnal and quarter-diurnal internal tides in the bay of biscay. part 1: Barotropic tides." Continental Shelf Research, 28(10-11), 1294-1315.

Parker, B. and Huff, L. (1998). "Modern under-keel clearance management." International Hydrographic Review, 75(2), 143-166.

Römisch, K. (1989). "Empfehlungen zur bemessung von hafeneinfahrten." Wasserbauliche Mitteilungen der Technischen Universitat Dresden, 1, 39-63.

Ross, L. and Sottolichio, A. (2016). "Subtidal variability of sea level in a macrotidal and convergent estuary." Continental Shelf Research, 131, 28-41.

Santoro, P., Fossati, M., and Piedra-Cueva, I. (2013). "Study of the meteorological tide in the río de la plata." Continental Shelf Research, 60, 51-63.

Schmidt, S. (2016). Le réseau MAGEST : bilan de 10 ans de suivi haute-fréquence de la qualité des eaux de l'estuaire de la Gironde. CNRS Éditions.

Sottolichio, A. and Castaing, P. (1999). "A synthesis on seasonal dynamics of highlyconcentrated structures in the gironde estuary." Comptes Rendus de l'Academie de Sciences - Serie lla: Sciences de la Terre et des Planetes, 329(11), 795-800.

Sys, C., Blauwens, G., Omey, E., Van De Voorde, E., and Witlox, F. (2008). "In search of the link between ship size and operations." Transportation Planning and Technology, 31(4), 435-463.

Tournadre, J. (2014). "Anthropogenic pressure on the open ocean: The growth of ship traffic revealed by altimeter data analysis." Geophysical Research Letters, 41(22), 79247932 cited By 54. 
Van, L. A. (2012). "Numerical modelling of sand-mud mixtures settling and transport processes: application to morphodynamic of the gironde estuary (france)." Ph.D. thesis, Université Paris-Est, Université Paris-Est.

van Maanen, B. and Sottolichio, A. (2018). "Hydro- and sediment dynamics in the gironde estuary (france): Sensitivity to seasonal variations in river inflow and sea level rise." Continental Shelf Research, 165, 37-50.

Vantorre, M., Candries, M., and Verwilligen, J. (2013). "Optimization of tidal windows for deep-drafted vessels by means of protoel." Next Generation Nautical Traffic Models, International workshop, Papers, 10.

Vantorre, M., Eloot, K., Delefortrie, G., Lataire, E., Candries, M., and Verwilligen, J. (2017). Maneuvering in Shallow and Confined Water. John Wiley \& Sons.

Yoshimura, Y. (1986). "Mathematical model for the maneuvering ship motion in shallow water." J. Kansai Soc. Nav. Arch. Japan, 1(200).

Zou, L. and Larsson, L. (2013). "Computational fluid dynamics (cfd) prediction of bank effects including verification and validation." Journal of Marine Science and Technology (Japan), 18(3), 310-323. 


\section{List of Tables}

1 Model performance parameters (Root Mean Square Error and Skill Score) for water levels with astronomical tide (AT) and NavTEL predictions at all tidal gages. . . . . . . . . . . . . . . . . . . . . . 27 
TABLE 1. Model performance parameters (Root Mean Square Error and Skill Score) for water levels with astronomical tide (AT) and NavTEL predictions at all tidal gages.

\begin{tabular}{lcccc}
\hline \multicolumn{1}{c}{ Tidal gages } & \multicolumn{2}{c}{ RMSE } & \multicolumn{2}{c}{ SS } \\
& AT & NavTEL & AT & NavTEL \\
\hline Le Verdon (8) & 0.13 & 0.15 & 0.987 & 0.983 \\
Richard (7) & 0.15 & 0.17 & 0.939 & 0.982 \\
Lamena (6) & 0.18 & 0.18 & 0.983 & 0.981 \\
Pauillac (5) & 0.19 & 0.20 & 0.981 & 0.980 \\
Le Marquis (2) & 0.23 & 0.15 & 0.977 & 0.990 \\
Bordeaux (0) & 0.31 & 0.22 & 0.964 & 0.982 \\
\hline
\end{tabular}




\section{List of Figures}

1 (a) Location map of the study area in the southwest of France and (b) the Gironde Estuary and its tributaries the Garonne and the Dordogne Rivers. The navigation channel is characterized by a dash grey line and stretches from the estuary mouth to the port of Bordeaux in the Garonne River, the main tributary. Black stars show tidal gauges located along the Estuary and blue squares show harbors including the Bordeaux Harbor. Depth-limited locations are represented by orange circles. (c) Numerical domain extending from the maritime part to the Dordogne River and the Garonne River. (d) The mesh is unstructured and composed of triangular elements with element sizes ranging from $80 \mathrm{~m}$ to $300 \mathrm{~m}$ for refined areas and the maritime part, respectively. (e) The Turbidity Maximum Zone (TMZ) is reproduced with a mud deposit of $2.6 \times 10^{6}$ tons in the central estuary and depicted by orange areas. . . . . . . . . . . . . . . . . . . . 30

2 Flow chart of NavTEL, a decision support tool used to schedule ship route and manage underkeel clearance in estuarine channels. NavTEL has a modular structure and a kernel composed of NAVIRE and TELBOT modules. The TELBOT module prepares and runs daily simulations with the TELEMAC-MASCARET modeling system. Numerical simulations incorporate real-time variations of river discharge and storm surges. The NAVIRE module post-processes the numerical outputs to provide the safest route and to predict allowable drafts. In the Figure, the kernel and the optional modules of NavTEL are indicated by gray and green boxes. NavTEL is written in Python 2.7 and is available as an open-source code at https:

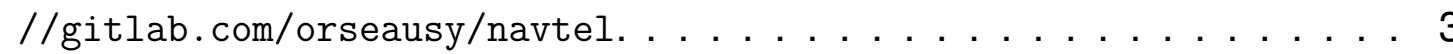


3 Comparison between measured and predicted free surface $(\mathrm{m})$ with astronomical tide (AT) (a-c) and with NavTEL simulations (d-f) at Le Verdon, Pauillac and Bordeaux stations. . . . . . . . . . . . . . . . . . . . . 32

4 Comparison of the difference in time of high water between measurements and predictions at (a) Le Verdon, (b) Pauillac and (c) Bordeaux stations. Predictions with only astronomical tide (AT) and with NavTEL are represented with black plus signs and red circles, respectively. . . . . . . . . 33

5 Temporal mean of the salinity over the numerical domain for the predicted period of the $03 / 19 / 2020$. At this period, the salt intrusion is restricted to the lower estuary at downstream Richard station. See Fig. 1b for locations. 34

6 Variations of the allowable draft along the navigation channel and for the predicted period from the 03/19/2020. The figure was generated for an arrival at the Bassens Aval terminal and for a ship draft of $10 \mathrm{~m}$. The black line indicates the start time for the safest route as well as the critical location where the maximum allowable draft where found. . . . . . . . . . . . . . . 35

7 Variations of the velocity (a), the salinity (b), the suspended particulate matter (c) and the predicted squat (d) along the navigation channel and for the safest route. The figure was generated for an arrival at the Bassens Aval terminal and for a ship draft of $8.3 \mathrm{~m} . \ldots \ldots \ldots$ 


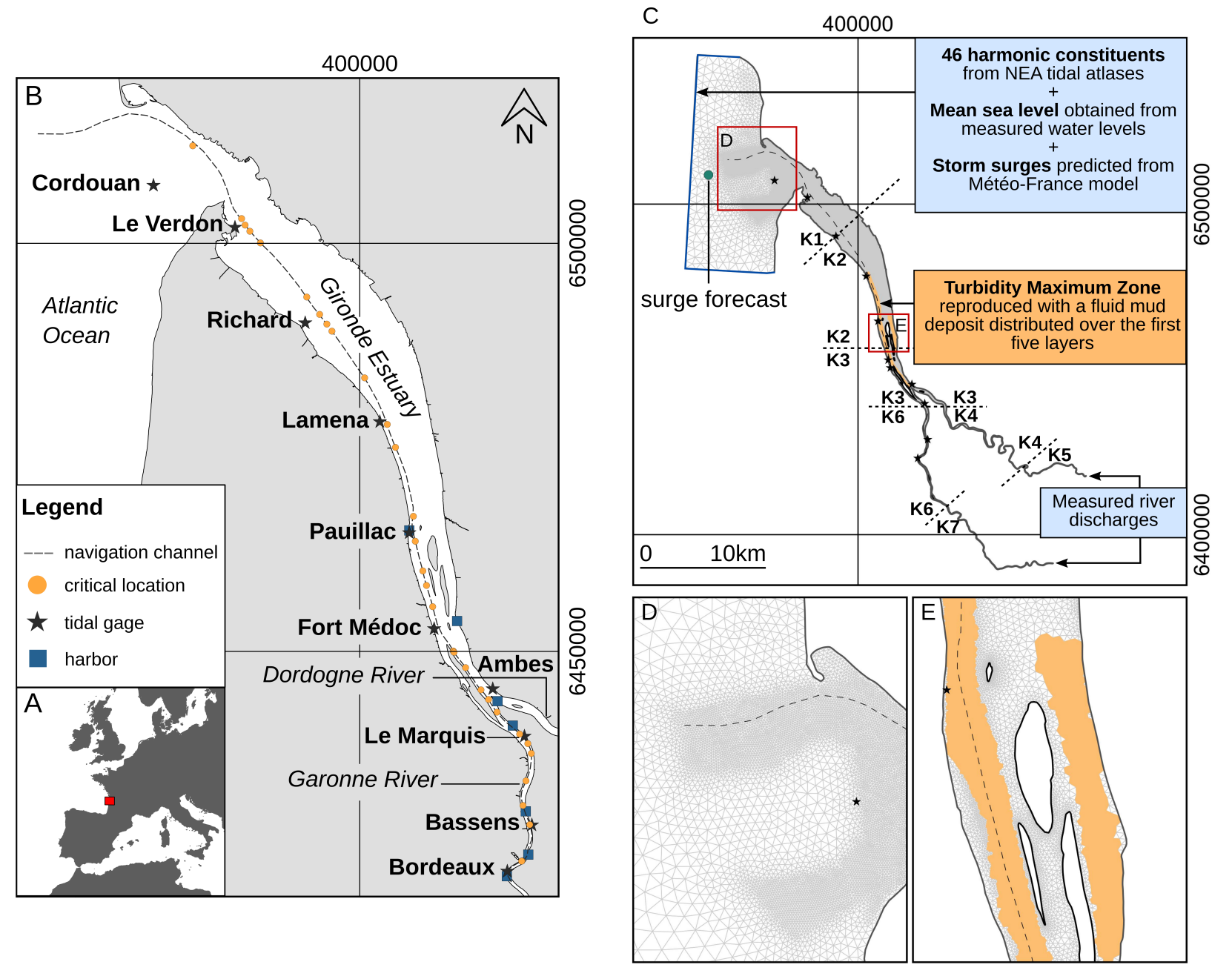

Fig. 1. (a) Location map of the study area in the southwest of France and (b) the Gironde Estuary and its tributaries the Garonne and the Dordogne Rivers. The navigation channel is characterized by a dash grey line and stretches from the estuary mouth to the port of Bordeaux in the Garonne River, the main tributary. Black stars show tidal gauges located along the Estuary and blue squares show harbors including the Bordeaux Harbor. Depthlimited locations are represented by orange circles. (c) Numerical domain extending from the maritime part to the Dordogne River and the Garonne River. (d) The mesh is unstructured and composed of triangular elements with element sizes ranging from $80 \mathrm{~m}$ to $300 \mathrm{~m}$ for refined areas and the maritime part, respectively. (e) The Turbidity Maximum Zone (TMZ) is reproduced with a mud deposit of $2.6 \times 10^{6}$ tons in the central estuary and depicted by orange areas. 


\section{TELBOT}

Module dedicated to preparing and

launching daily simulations with the

Opentelemac-based numerical model.

\section{DAILY SIMULATION}

\section{Inputs}

- measured river discharge

- storm surge forecasts

- salinity distribution

- suspended-sediment

concentrations

\section{Outputs}

- numerical output of 18 days (including 3 days forecast) with water levels, tidal currents and density gradients.
Ship arrivals in $36 \mathrm{~h}$

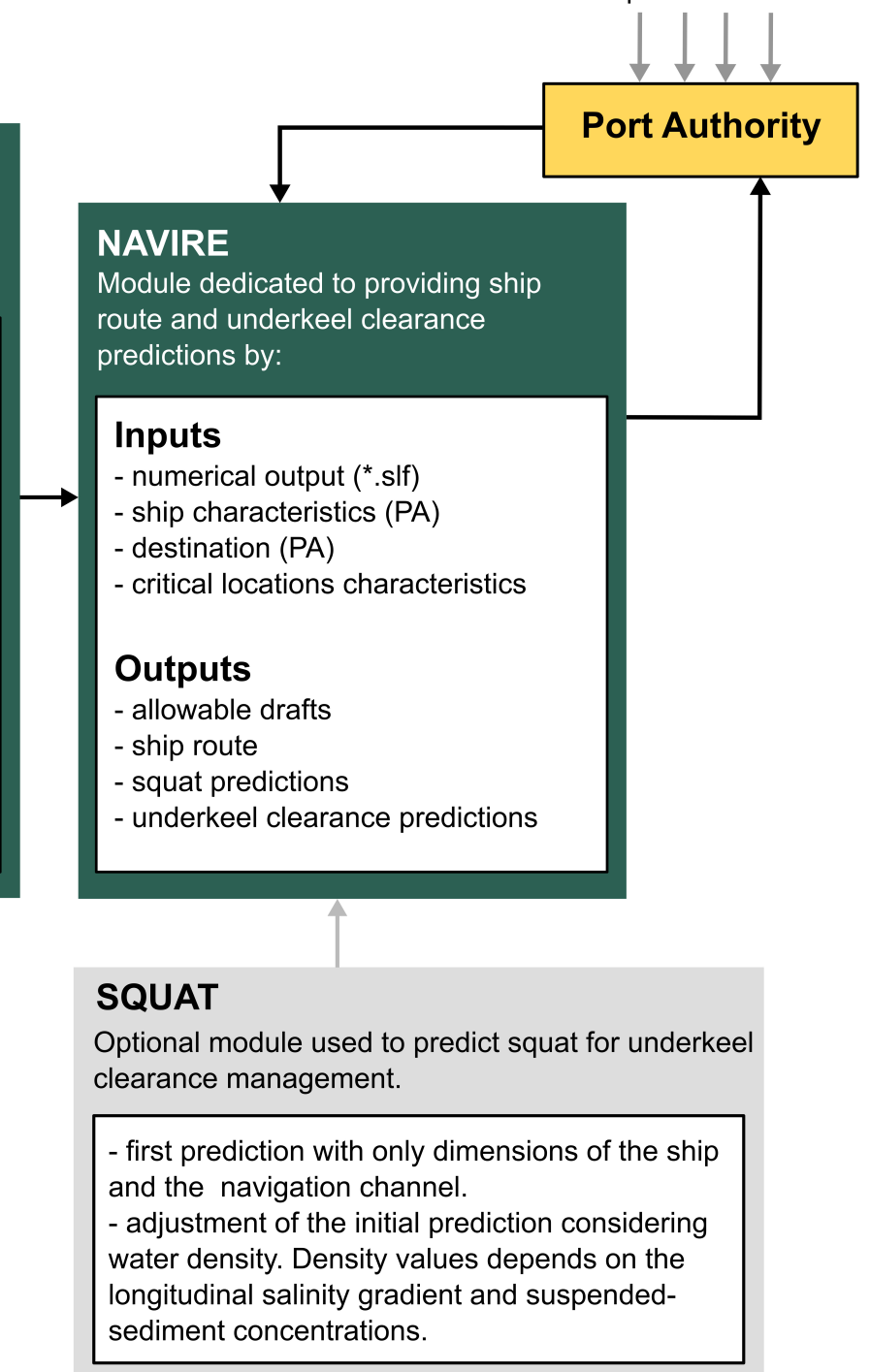

Fig. 2. Flow chart of NavTEL, a decision support tool used to schedule ship route and manage underkeel clearance in estuarine channels. NavTEL has a modular structure and a kernel composed of NAVIRE and TELBOT modules. The TELBOT module prepares and runs daily simulations with the TELEMAC-MASCARET modeling system. Numerical simulations incorporate real-time variations of river discharge and storm surges. The NAVIRE module post-processes the numerical outputs to provide the safest route and to predict allowable drafts. In the Figure, the kernel and the optional modules of NavTEL are indicated by gray and green boxes. NavTEL is written in Python 2.7 and is available as an open-source code at https://gitlab.com/orseausy/navtel. 


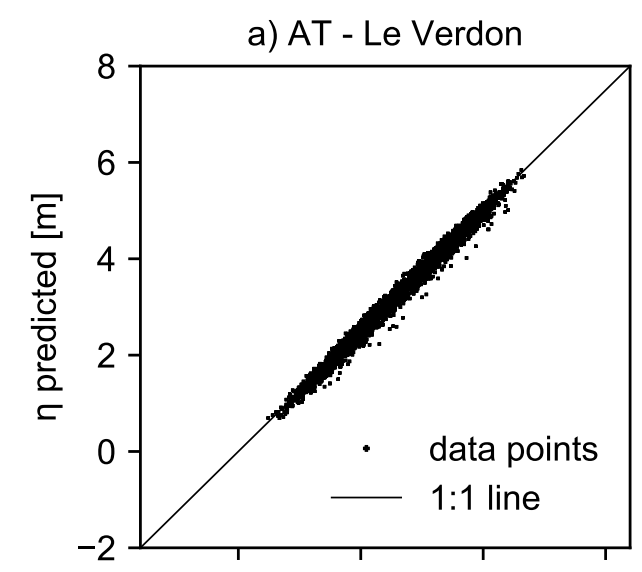

d) NavTEL - Verdon

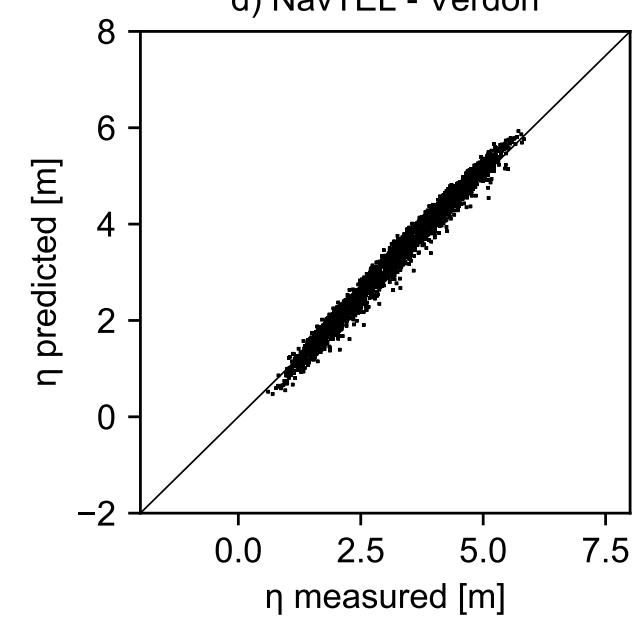

b) AT - Pauillac

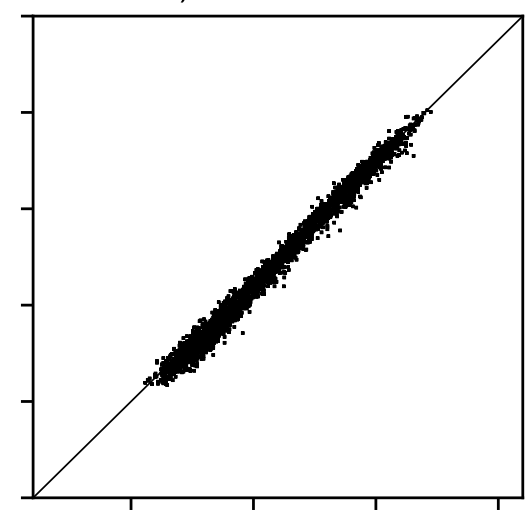

e) NavTEL - Pauillac

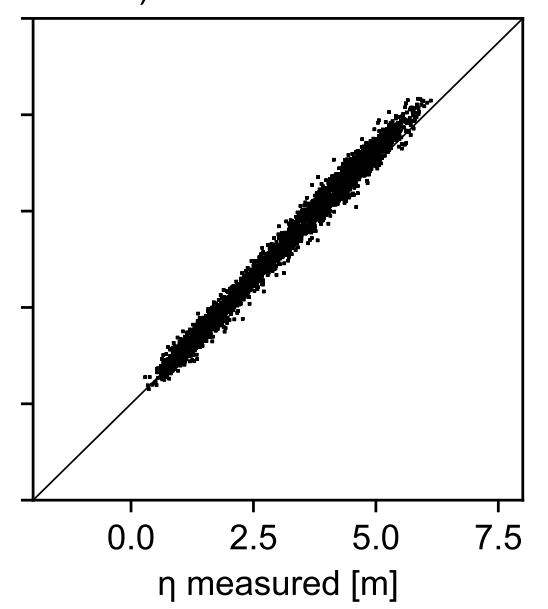

c) AT - Bordeaux

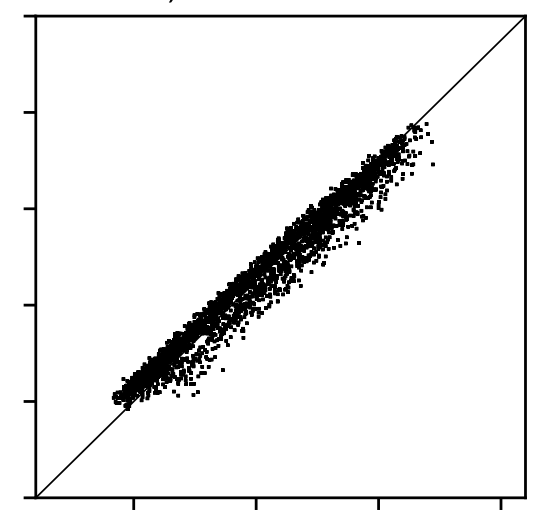

f) b - Bordeaux

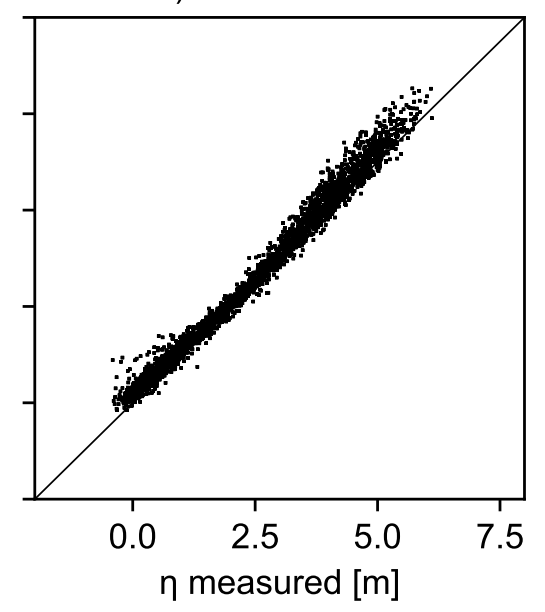

Fig. 3. Comparison between measured and predicted free surface $(\mathrm{m})$ with astronomical tide (AT) (a-c) and with NavTEL simulations (d-f) at Le Verdon, Pauillac and Bordeaux stations. 

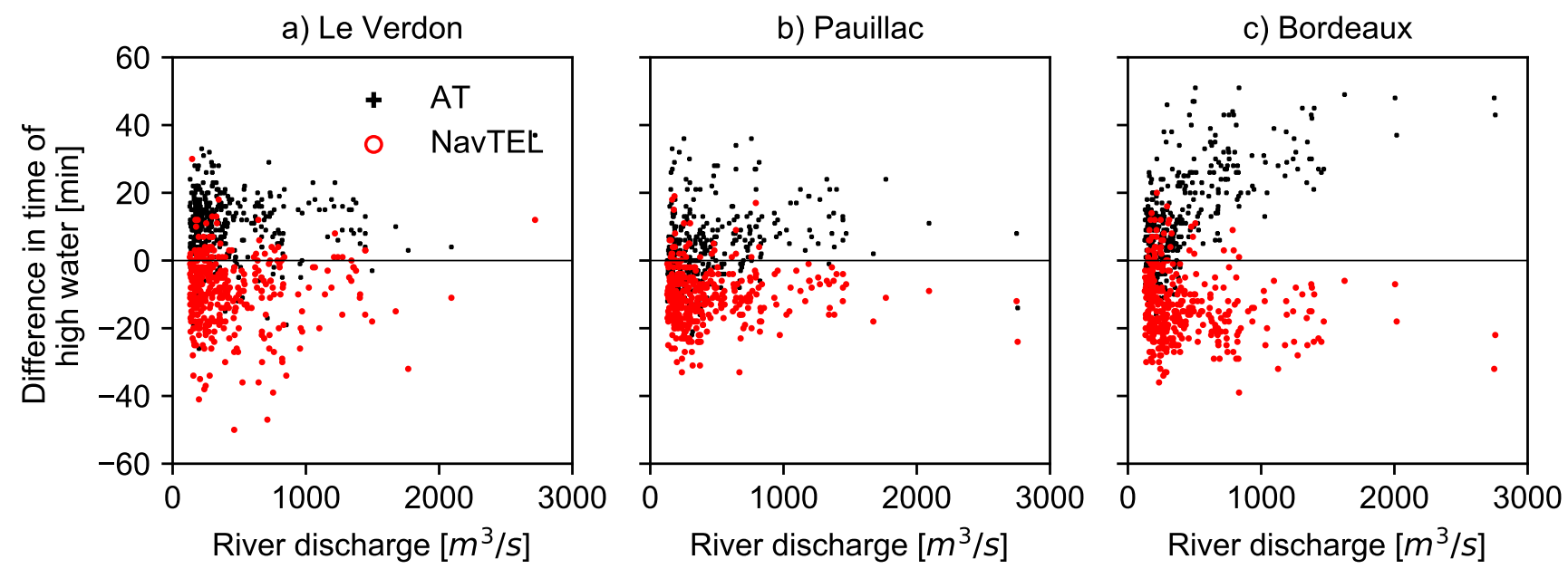

Fig. 4. Comparison of the difference in time of high water between measurements and predictions at (a) Le Verdon, (b) Pauillac and (c) Bordeaux stations. Predictions with only astronomical tide (AT) and with NavTEL are represented with black plus signs and red circles, respectively. 


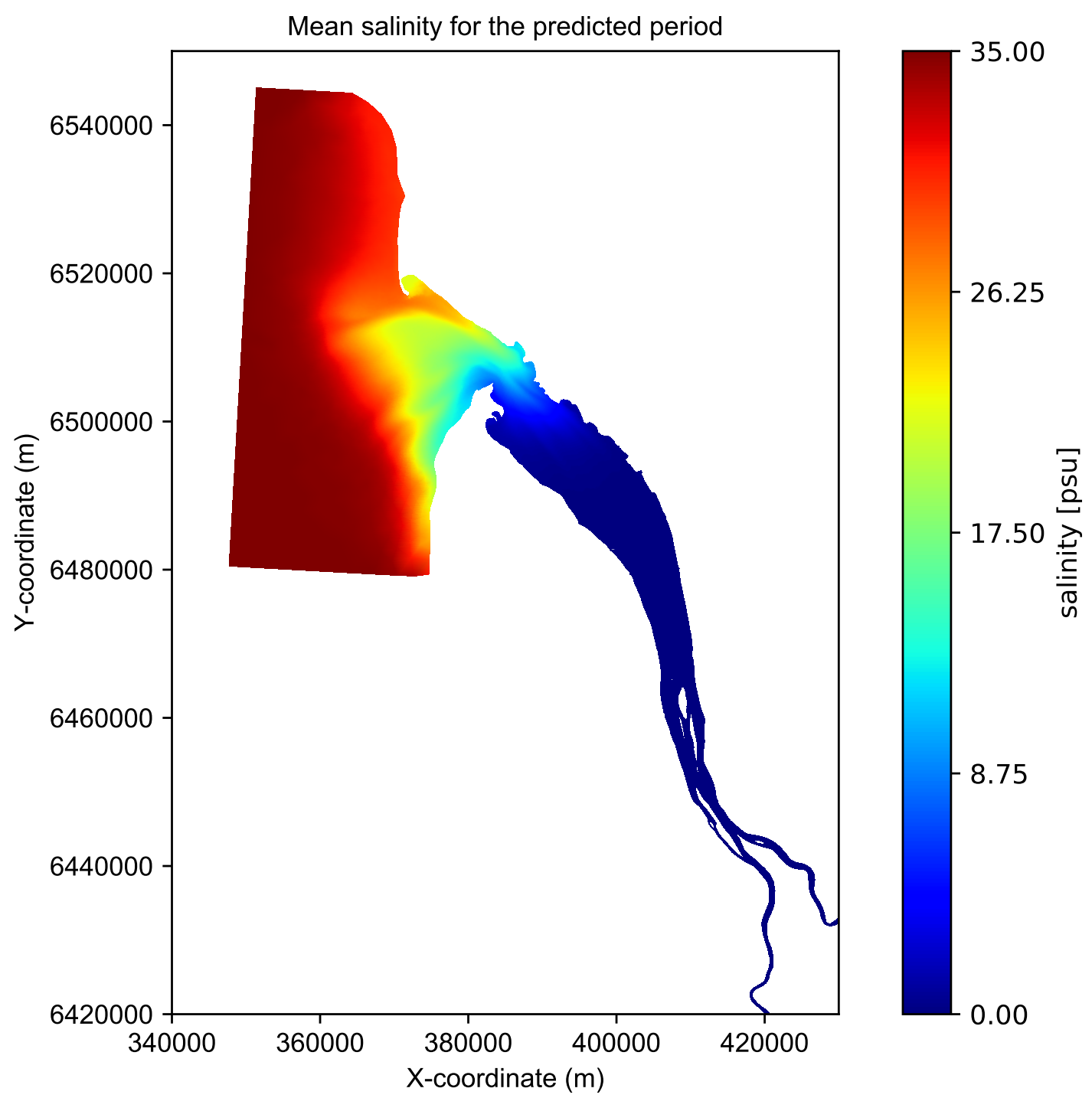

Fig. 5. Temporal mean of the salinity over the numerical domain for the predicted period of the $03 / 19 / 2020$. At this period, the salt intrusion is restricted to the lower estuary at downstream Richard station. See Fig. 1b for locations. 


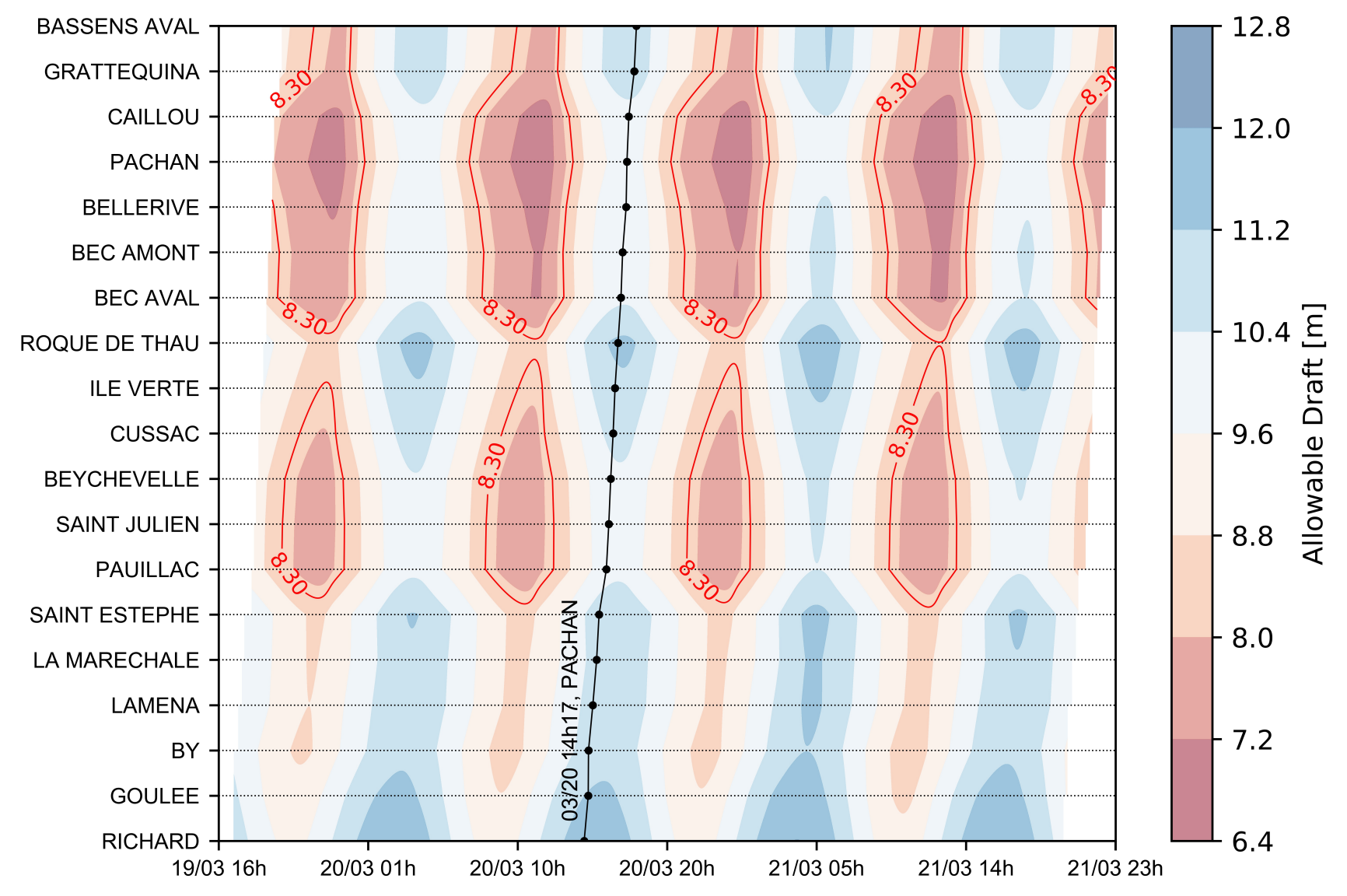

Fig. 6. Variations of the allowable draft along the navigation channel and for the predicted period from the 03/19/2020. The figure was generated for an arrival at the Bassens Aval terminal and for a ship draft of $10 \mathrm{~m}$. The black line indicates the start time for the safest route as well as the critical location where the maximum allowable draft where found. 

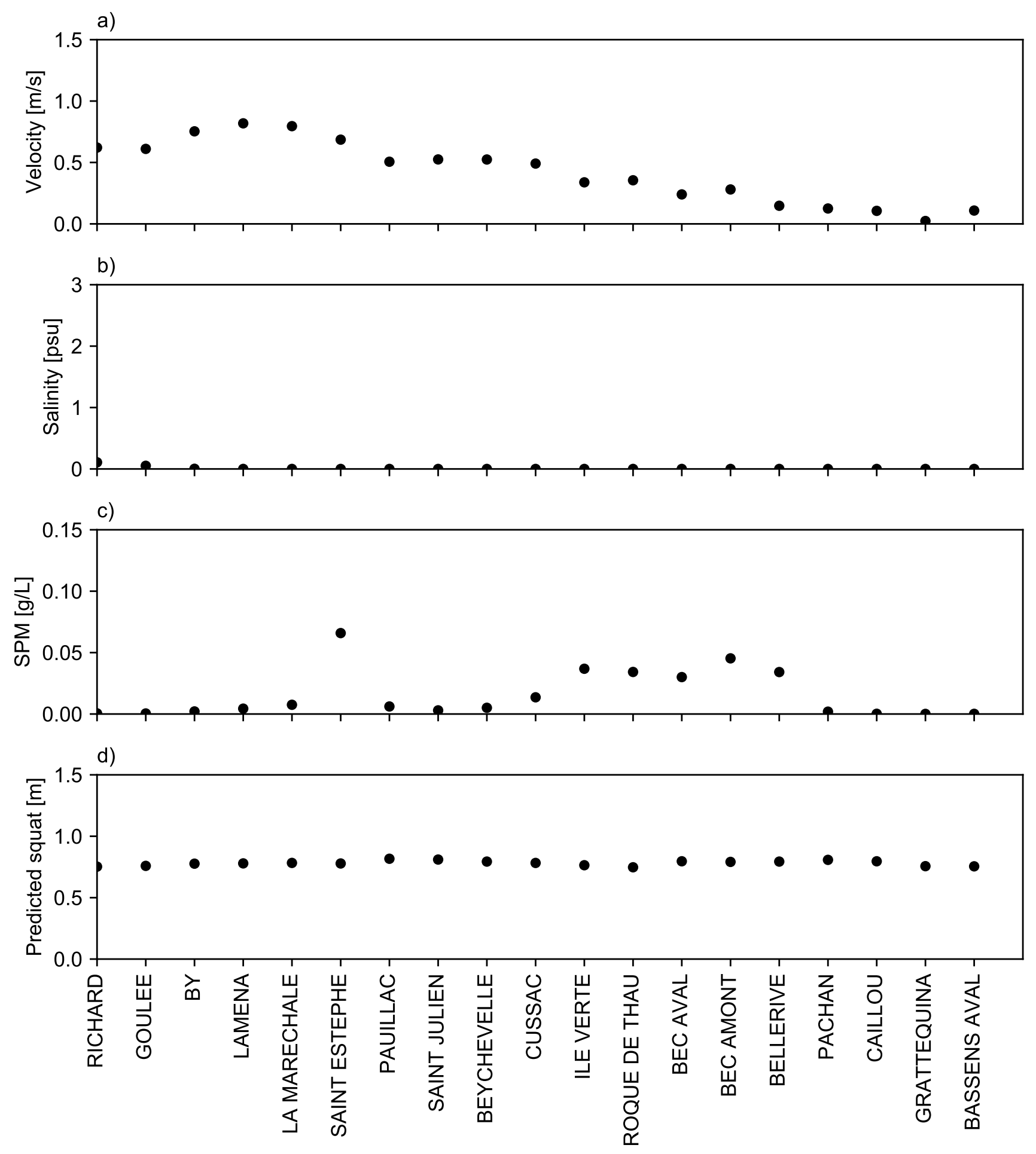

Fig. 7. Variations of the velocity (a), the salinity (b), the suspended particulate matter (c) and the predicted squat (d) along the navigation channel and for the safest route. The figure was generated for an arrival at the Bassens Aval terminal and for a ship draft of $8.3 \mathrm{~m}$. 